\title{
Hot topic: Effect of breeding strategies using genomic information on fitness and health
}

\author{
C. Egger-Danner, ${ }^{* 1}$ A. Willam, † C. Fuerst, ${ }^{*}$ H. Schwarzenbacher, ${ }^{\star}$ and B. Fuerst-Waltl† \\ *ZuchtData EDV-Dienstleistungen GmbH, Dresdner Str. 89/19, 1200 Vienna, Austria \\ †Division of Livestock Sciences, Department of Sustainable Agricultural Systems, University of Natural Resources and Life Sciences Vienna, \\ Gregor-Mendel-Str. 33, 1180 Vienna, Austria
}

\section{ABSTRACT}

A complex deterministic approach was used to model the breeding goal and breeding structure for the Austrian Fleckvieh (dual-purpose Simmental) breed. The reference breeding goal corresponded to the current total merit index (TMI-R), where dairy traits have a relative weight of $37.9 \%$ and fitness traits of $43.7 \%$ (beef traits $16.5 \%$; milkability $2 \%$ ). The breeding program was characterized by 280,000 cows under performance recording, 3,200 bull dams, 100 test bulls with a test capacity of $25 \%$, and 15 proven bulls and 8 bull sires per year. The annual monetary genetic gain (AMGG) was generated mainly by increases in milk fat and milk protein yield $(80.6 \%)$ and only to a small extent by fitness traits $(6.6 \%)$. The inclusion of direct health traits (early reproductive disorders, cystic ovaries, and mastitis) with their economic weights increased the relative AMGG for fitness traits from 6.6 to $11.2 \%$. The presently slightly negative AMGG for fertility index and udder health changed in a positive direction. Increasing the weight on the direct health traits by $50 \%$ resulted in a further shift toward fitness and health. The effect of strategies using genomic information in a total merit index (TMI) with varying weights on fitness and health traits was also analyzed. The conventional progenytesting scheme was defined as the reference breeding program. A breeding program was considered to be genomically enhanced (GS50) when $50 \%$ of inseminations of herdbook cows and of bull dams were from young bulls with a genomic TMI, and a second program (GS100) did not rely on progeny-tested bulls at all. For GS50, a clear shift of the relative gain in AMGG toward fitness and health traits was observed for all 3 TMI scenarios, as a result of larger progeny groups and a shorter generation interval. For GS100, where no gene flow from progeny-tested bulls was assumed, the genetic gain per generation was lower for the fertility

Received January 5, 2012.

Accepted April 24, 2012.

${ }^{1}$ Corresponding author: egger-danner@zuchtdata.at and udder health index but higher per year. The results based on natural genetic gain per year showed that no positive genetic response for fertility and udder health index were achieved for TMI-R (without the inclusion of direct health traits) in GS50 and GS100. The direction of the genetic trend was determined by the weights given to fertility and udder health indices within the TMI. When appropriate weights generated a clear positive trend, GS50 and GS100 reinforced this trend.

Key words: genomic selection, breeding program, health trait, fitness trait

\section{INTRODUCTION}

Because of the development of genomic breeding values, breeding programs are undergoing major restructuring worldwide. An increase in genetic gain per year of up to $100 \%$ is expected (Schaeffer, 2006). Breeding programs, breeding goals, and the possibilites of performance recording also need to be reconsidered. Interest in the introduction of novel traits is growing. Economic aspects of dairy production and consumer concerns regarding animal welfare and food safety increase the need to improve fitness and health traits internationally. Additionally, a strong increase in production has been achieved within the last decades. Milk yield has more than doubled in many countries within the last 40 yr. The increase in milk yield is accompanied by lower reproduction performance and an increase in health disorders (Oltenacu and Algers, 2005). Results based on performance recording show a genetic trend for milk $\mathrm{kg}$ of $92 \mathrm{~kg}$ per year across the last 10 years for Fleckvieh (dual-purpose Simmental) cattle in Austria. The genetic level in fitness could not be improved within the same period (ZuchtData, 2010). A survey of Austrian cattle breeders showed that primarily, strong genetic improvements in fertility, udder health, and feet and legs are desired, but only a moderate improvement in milk and beef traits is desired over the next $10 \mathrm{yr}$. To strengthen the fitness and health complex, the Federation of Austrian Cattle Breeders has set up a health monitoring system to register veterinary diagnoses and 
use it for breeding, management, and prevention (Austrian Ministry of Health, 2010; Egger-Danner et al., 2010, 2012; Koeck et al., 2010a,b).

Various publications have shown a negative genetic correlation between milk yield and functional traits (Veerkamp et al., 2003; Fuerst and Fuerst-Waltl, 2006). According to Philipsson and Linde (2003), deterioration in reproduction and health is to be expected if the selection weight is strongly on milk traits. Results from Nordic countries (Svendsen and A.-Ranberg, 2000; Heringstad et al., 2003, 2007) have demonstrated that a higher economic weight for the udder health index in the total merit index (TMI) generates a favorable genetic gain for clinical masitits with a yearly reduction in incidence rate of $0.3 \%$. In Norway, the weight for the udder health index was increased from 3 to 21\% between 1978 and 2009 (Heringstad et al., 2001; Heringstad, 2009; Geno, 2012). Odegård et al. (2003) showed that the predictive ability (measured as the mean daughter deviations for clinical mastitis among second-crop daughters, regressed on predicted transmitting abilities for clinical mastitis and lactation mean SCS in first-crop daughters) was 23 to $43 \%$ higher for clinical mastitis than for lactation mean SCS. Predictive ability improved by 8 to 13 percentage points when information on both traits was utilized compared with single-trait selection. The relative weight that should be assigned to standardized predicted transmitting abilities from univariate genetic analyses were 60 to $67 \%$ for clinical mastitis and 33 to $40 \%$ for lactation mean SCS.

Lassen et al. (2007) proposed approximate multitrait models using preadjusted data rather than full linear multitrait models when evaluating and selecting for many correlated traits. These models are especially advantageous if many traits are combined in the TMI, because correlations between the traits are not neglected. According to Hansen Axelsson et al. (2011), if the main economic emphasis was still on protein yield, the deterioration of functional traits in multiple-traits settings was not halted, even when new indicator traits were included and a more advanced recording system was implemented for functional traits.

Concerning genomic selection, different studies showed a positive effect on functional traits (Neuner and Götz, 2011; Buch et al., 2012). Lillehammer et al. (2011) pointed out that the relative superiority of a genomic selection scheme decreased as the heritablity of the traits increased.

One objective of this paper is to analyze the effect of including direct health traits (DHT) in the TMI and to evaluate the impact of genomic selection in the breeding scheme on the annual monetary genetic gain
(AMGG). Another objective was to assess the effect of these measures on the annual natural genetic gain for different dairy and fitness traits, DHT, and indices in Austrian Fleckvieh. Particularly, the possible improvement of fertility and udder health based on DHT and the possibility of genomic evaluation were investigated by comparing different TMI scenarios for 3 breeding strategies.

\section{MATERIALS AND METHODS}

The computer software ZPLAN (Willam et al., 2008) optimizes selection strategies in livestock breeding using a purely deterministic approach. The gene flow method and selection index procedures constitute the core of the software. It evaluates both the genetic and economic efficiency of breeding strategies. The user defines selection groups in the whole population, each with a specific selection intensity, and other individual information sources used in the index. Additionally, population and cost parameters as well as biological parameters must be defined for each selection group. The program calculates several criteria, such as AMGG for the aggregate genotype, annual genetic gain (AGG) for single traits, discounted return, discounted costs, and discounted profit for a given investment period. The criteria for evaluating alternative breeding programs used in this study were AMGG, the monetary superiority per year of the progeny of the selected animals after one selection round in the breeding unit, and AGG, the natural genetic gain per year.

\section{Population Structure and Cost Parameters}

The study was carried out for dual-purpose Fleckvieh cattle, as genetic and economic parameters for DHT are available for this breed (Koeck et al., 2010a,b; EggerDanner et al., 2010; Fuerst-Waltl et al., 2010; Fuerst et al., 2011a; Fuerst and Fuerst-Waltl, 2011; EggerDanner et al., 2012). In addition, DHT are routinely genetically evaluated (Fuerst et al., 2011a), and a joint routine genomic evaluation for Fleckvieh in Austria and Germany (Edel et al., 2011a,b) was implemented recently. The Fleckvieh population in Austria consists of about 510,000 cows, with 280,000 cows registered in the herdbook.

The essential input parameters used for modeling the different breeding strategies were based on the evaluation of the breeding program Fleckvieh Austria (ZuchtData, 2010; Table 1). The costs were average costs based on calculations by the breeding organizations and AI centers (Egger-Danner et al., 2000), adjusted for the current circumstances and inflation. Of 
Table 1. Essential input parameters for modeling the breeding program Fleckvieh Austria for the 3 breeding strategies: conventional progenytesting program (CPT), genomic selection with 50\% insemination of young bulls (GS50), and genomic selection with 100\% inseminations of young bulls (GS100) ${ }^{1}$

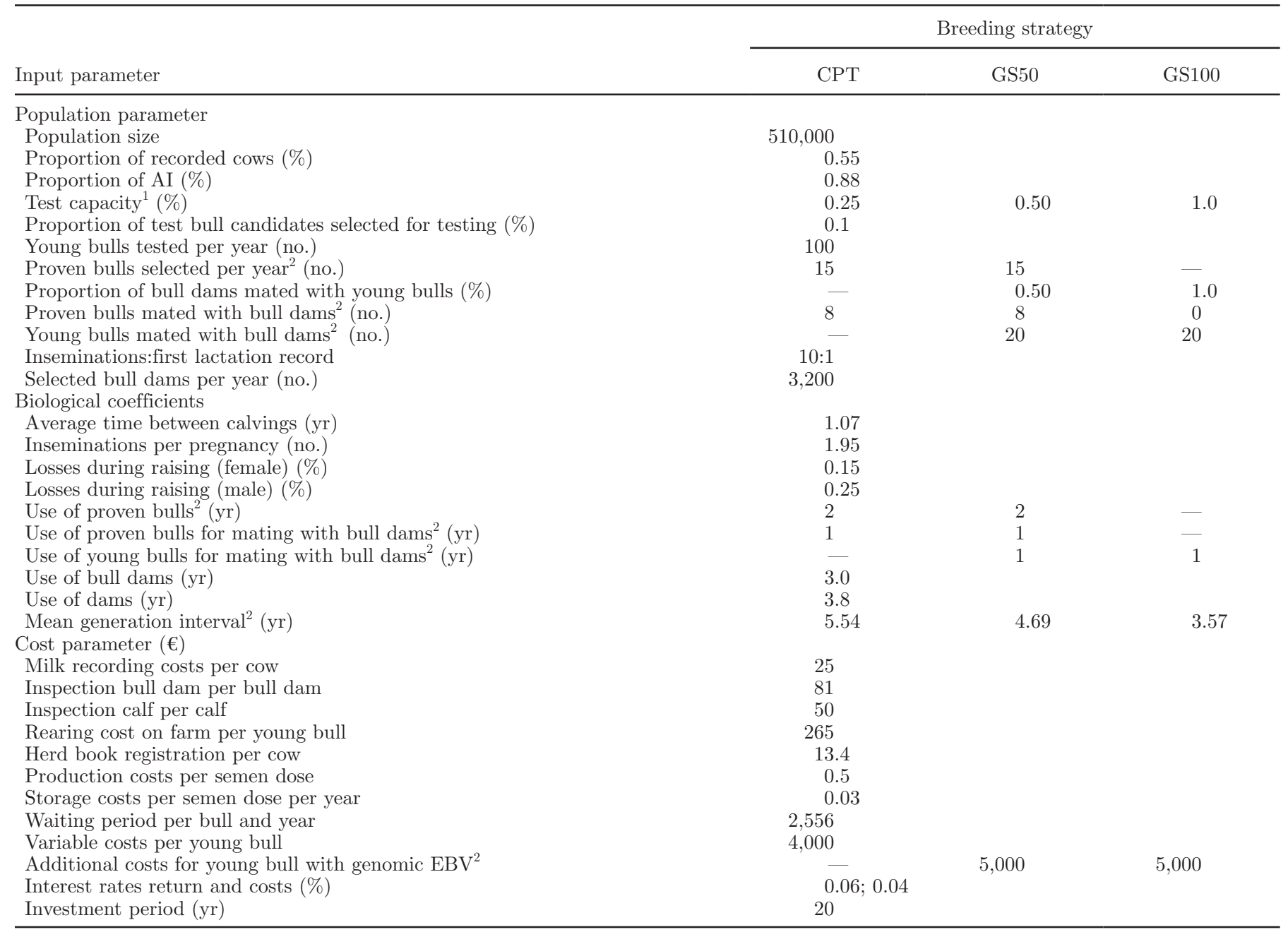

${ }^{1}$ Only changes in parameters are indicated in GS50 and GS100.

${ }^{2}$ Indicates changes in parameters between different breeding schemes.

the milk recording costs, $50 \%$ were assumed related to breeding purposes. Concerning semen policy, a system with waiting bulls was assumed. From all bulls, 5,000 doses of semen were stored in addition. The variable costs per test bull consisted of incentives paid to the farmer for progeny records and costs associated with the description of conformation traits.

\section{Genetic Parameters}

Heritabilities and phenotypic and genetic correlations used for calculating a selection index in ZPLAN are given by Neuner and Götz (2011) and Fuerst and Fuerst-Waltl (2006). The genetic parameters for the DHT are from Koeck et al. (2010a,b), and the correla- tions to the type traits from Fuerst et al. (2010) and Fuerst and Fuerst-Waltl (2011). The assumed heritabilities were 0.02 for the aggregate fertility index and 0.12 for the udder health index. The genetic correlation between fat and protein yields and the fertility index was -0.2 , and that between fat and protein yields and the udder health index was -0.25 (Neuner and Götz, 2011).

\section{TMI and Breeding Strategies}

The present TMI of Fleckvieh cattle without inclusion of DHT was used as the reference index (TMI-R). A TMI including DHT according to their economic weight $(\mathbf{T M I}+\mathbf{D H T})$, and a TMI with a weight on 
fertility and udder health index increased by $50 \%$ (TMI+DHT50) were defined as alternative scenarios. A conventional progeny-testing program (CPT), a genomic-enhanced breeding program where $50 \%$ of the inseminations were from young bulls (GS50), and a full genomic breeding program (GS100) were applied to the 3 TMI. For GS50 and GS100, additional costs for preselection of candidates and genotyping and the higher costs of young bulls were taken into account. For CPT and GS50, all 100 bulls were kept as waiting bulls. For GS100, no costs were associated with waiting bulls.

$\boldsymbol{T M I}-\boldsymbol{R}$. The breeding goal in Austria and Germany corresponds to the TMI of Miesenberger (1997). The economic weights were updated using the results from Lind (2007). Based on these results, the relative weight in the present Fleckvieh breeding goal for dairy traits is $38 \%$, for beef traits $16 \%$, for fitness traits $44 \%$, and for milkability 2\% (Fuerst et al., 2011b). Additive genetic standard deviations and economic weights per additive genetic standard deviation of the single traits are shown in Table 2. The present female fertility index (Fert-I) consists of nonreturn rate at $56 \mathrm{~d}$ for heifers and cows, and time between first and last insemination for heifers and cows. For the udder health index (UH-I), however, only SCC is currently considered. No DHT are currently included in the TMI-R in Austria and Germany.

$\boldsymbol{T M I + D H T}$. A TMI including DHT was developed based on results from a health monitoring project in Austria (Fuerst et al., 2010, 2011a; Koeck et al., 2010a,b; Egger-Danner et al., 2012), in which the recording of veterinarian diagnoses was established and a routine genetic evaluation was introduced.
The presently used female fertility index (Fert-I) with its economic weight $(\mathbf{E W})$ of $€ 15$ per genetic standard deviation $\left(\mathbf{s}_{\mathbf{A}}\right)$ was extended by including early reproductive disorders and cystic ovaries, with their own economic weights of $€ 9.34 / \mathrm{s}_{\mathrm{A}}$ and $€ 4.09 / \mathrm{s}_{\mathrm{A}}$, respectively. These weights were calculated based on the frequencies of diagnoses using the Austrian Health Monitoring data and extra costs of medicine and labor (Fürst-Waltl et al., 2010). Therefore, the EW of the new fertility index was increased from $€ 15.00 / \mathrm{s}_{\mathrm{A}}$ to $€ 28.43 / \mathrm{s}_{\mathrm{A}}$ by including the respective DHT (Table 2 ).

An udder health index (UH-I) was used in this study. In addition to SCC, clinical mastitis, and the type traits udder score, udder depth, suspensory ligament, fore udder attachment, and teat placement were considered as indicator traits without an additional EW. The costs of mastitis were already included in the derivation of the EW for SCC (Lind, 2007); thus, no additional EW was put on udder health for TMI+DHT.

$\boldsymbol{T M I + D H T 5 0}$. The TMI+DHT50 breeding goal consisted of the same traits and genetic parameters as TMI+DHT. However, the EW of fertility and udder health index were increased by $50 \%$ (Table 2) to calculate the AGG of the different traits. In contrast, the AMGG were calculated based on the realistic EW of TMI-DHT to avoid overestimating the achievable AMGG for fertility and udder health indices.

The present breeding scheme for Fleckvieh Austria was established in 2000 (Egger-Danner et al., 2000) as a progeny-testing program, where about 1,500 bull dams and approximately 140 test bulls were selected and tested before the introduction of genomic evaluation.

Table 2. Additive genetic standard deviation $\left(\mathrm{s}_{\mathrm{A}}\right)$, economic weight per $\mathrm{s}_{\mathrm{A}}\left(\mathrm{EW} / \mathrm{s}_{\mathrm{A}}\right)$ in Euros, and economic weight in percent $(\mathrm{EW} \%)$ of the single traits in the different total merit indices TMI-R, TMI+DHT, and TMI+DHT50 for Austrian Fleckvieh cattle ${ }^{1}$

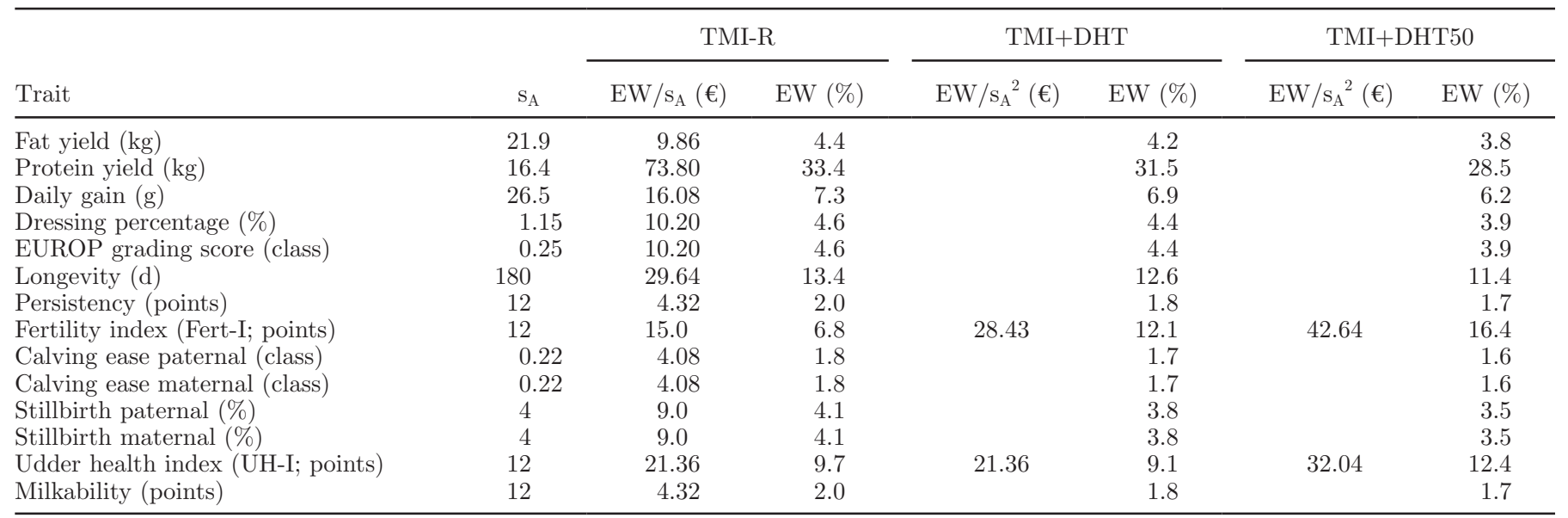

${ }^{1}$ TMI-R $=$ total merit index reference (udder health index contains SCC only); TMI+DHT $=$ total merit index with direct health traits; TMI+DHT50 = total merit index with direct health traits increased by $50 \%$ of economic weight.

${ }^{2}$ Only changes in EW/ $\mathrm{s}_{\mathrm{A}}$ are indicated for TMI+DHT and TMI+DHT50. 


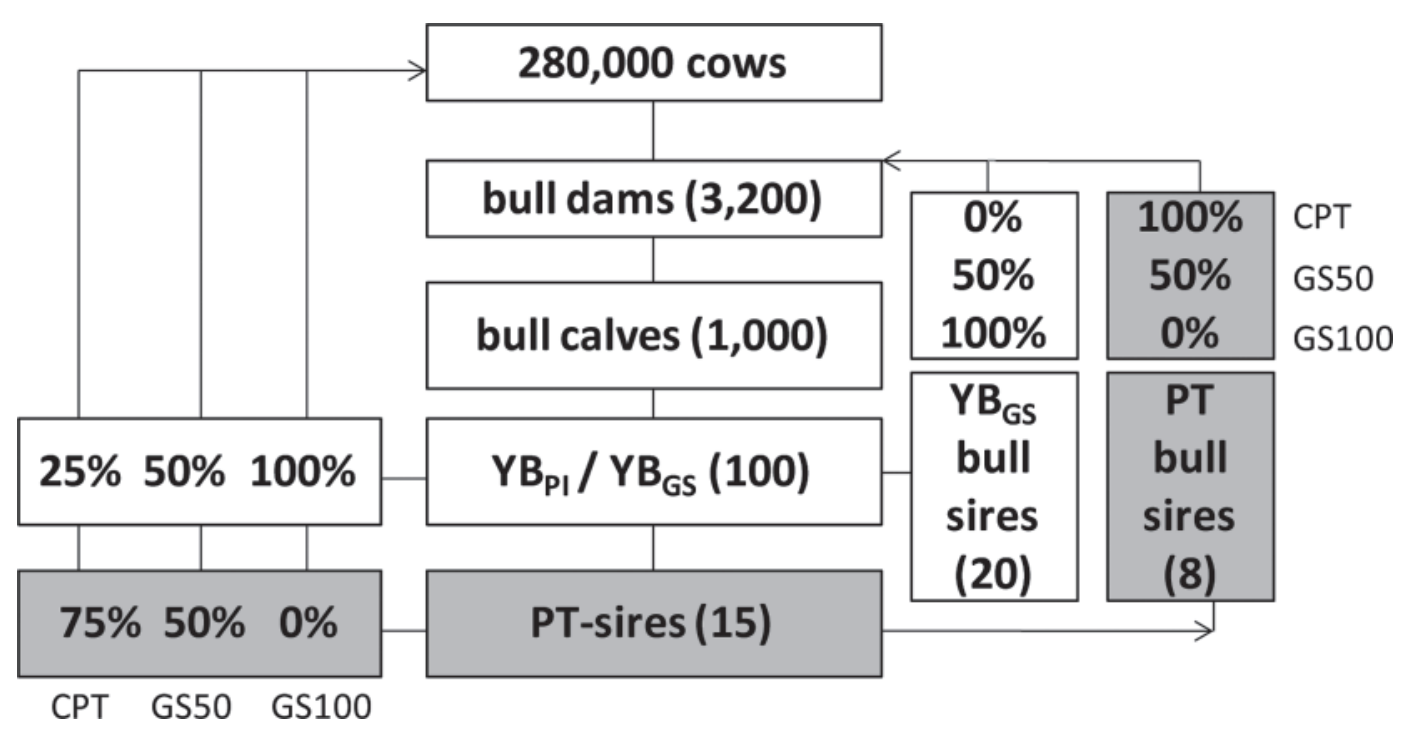

Figure 1. Structure of the breeding strategies conventional progeny-testing program (CPT), genomic selection with $50 \%$ insemination with young bulls (GS50), and genomic selection with $100 \%$ insemination of young bulls (GS100). $\mathrm{YB}_{\mathrm{PI}}=$ young bulls with pedigree information, YB $\mathrm{GS}_{\mathrm{GS}}$ = young bulls with pedigree and genomic information, $\mathrm{PT}=$ progeny tested.

The preselection intensity of the test bulls was 4 out of 10 male calves, and on average about 60 daughter records per test bull were obtained. Out of each batch of 140 bulls, the best 25 bulls were used for mating and the best 8 bulls (bull sires) were chosen for elite matings with bull dams.

For this study, 3 breeding strategies were compared (Figure 1). For CPT, essentially the same selection intensities were assumed as in the genomic selection scheme. The reason for this is that the effect of the major effects of genomic selection, such as higher reliabilities and shorter generation intervals, can be analyzed more clearly.

$\boldsymbol{C P T}$. The CPT represents an improvement to the present breeding program Fleckvieh Austria. A preselection of 0.1 (1 out of 10 male calves) was used. Out of 1,000 male calves from about 3,200 bull dams, 100 test bulls were selected, with a proportion of $25 \%$ of test bull inseminations. Fifteen proven sires out of the 100 test bulls were chosen each year for insemination of the cow population and used for 2 yr. Out of the 15 proven bulls, 8 sires were selected for elite matings with bull dams each year.

GS50. Fifty percent of the cow population and bull dams were mated with young bulls. Young bulls are genotyped bulls that are preselected based on their genomic breeding value, where pedigree and genomic information are combined (Edel et al., 2011a). The 20 best of the 100 young bulls were used for $50 \%$ of the inseminations of the bull dams.

GS100. Only young bulls were used for mating with the cow population and bull dams. The number of the selected animals in the different selection groups was not changed.

\section{Reliability of TMI}

The computer program ZPLAN calculates the reliability of the TMI based on the different sources of information (e.g., own performance, halfsibs, progeny) for each selection group separately. The additional gain in information based on direct genomic values was modeled by accounting for additional progeny equivalents. The reliabilities of the bull groups for the different TMI and the different breeding strategies are shown in Table 3 . The progeny equivalents assumed for dairy traits, fertility index, and udder health index, were 12, 80, and 25 daughter records, respectively. The calculation is based on the formula for the correlation between true and estimated breeding value, where heritability and number of progeny are considered (Willam and Simianer, 2011). The increase in reliability due to genomic information is according to the results from the joint routine genetic evaluation of Austria and Germany (Edel et al., 2011a,b).

\section{RESULTS AND DISCUSSION}

\section{DHT Included in the TMI}

The analyses of an optimized conventional breeding scheme and 2 genomic selection strategies were compared (Figure 1). For the CPT program, the AMGG for 
Table 3. Reliabilities of total merit indices for young bulls based on pedigree index $\left(\mathrm{YB}_{\mathrm{PI}}\right)$, young bulls based on genomic information $\left(\mathrm{YB}_{\mathrm{GS}}\right)$, and proven progeny-tested bull (PT-bull) for the different breeding strategies (CPT, GS50, GS100) and total merit indices (TMI-R, TMI+DHT, TMI+DHT50)

\begin{tabular}{lccc}
\hline Strategy and index & YB $_{\mathrm{PI}}$ & $\mathrm{YB}_{\mathrm{GS}}$ & PT-bull \\
\hline CPT, TMI-R & 0.33 & & 0.85 \\
CPT, TMI+DHT & 0.32 & & 0.83 \\
CPT, TMI+DHT50 & 0.31 & & 0.79 \\
GS50, TMI-R & & 0.59 & 0.88 \\
GS50, TMI+DHT & & 0.58 & 0.86 \\
GS50, TMI+DHT50 & 0.57 & 0.83 \\
GS100, TMI-R & & 0.59 & \\
GS100, TMI+DHT & 0.58 & \\
GS100, TMI+DHT50 & & 0.57 & \\
\hline
\end{tabular}

${ }^{1} \mathrm{CPT}=$ conventional progeny-testing program; GS50 = genomic selection with $50 \%$ insemination of young bulls; GS100 = genomic selection with $100 \%$ inseminations of young bulls; TMI-R = total merit index reference (udder health index contains SCC only); TMI+DHT $=$ total merit index with direct health traits; TMI+DHT50 = total merit index with direct health traits increased by $50 \%$ of economic weight.

the 3 different total merit indices (TMI-R, TMI+DHT, TMI+DHT50) are listed in Table 4.

As shown in Table 2, the relative weights in TMI-R were $37.8 \%$ for dairy traits (fat and protein yields) and $43.7 \%$ for fitness traits. Despite the high weight for fitness traits, only $6.6 \%$ of AMGG was related to fitness traits, whereas gains in dairy traits accounted for $80.6 \%$ (Table 4), and the expected trends for fertility index and udder health index were negative. This is in agreement with the results of Neuner and Götz (2011).

Including DHT increased the total AMGG just slightly from $€ 24.10$ to $€ 24.23$, whereas the total AMGG of
TMI+DHT50 was slightly lower compared with that of TMI-R and TMI+DHT. This is caused by the fact that to calculate the AMMG of TMI+DHT50, the realistic EW of Fert-I and UH-I were considered (Table 2, TMI+DHT), and not those increased by $50 \%$ used to calculate the AGG of Fert-I and UH-I. Considering DHT resulted in a shift of relative AMGG to fitness traits (11.2 and $19.5 \%$ versus $6.6 \%$ ). For TMI+DHT, the relative contribution of dairy traits to AMMG was reduced to $76.3 \%$, whereas that of fitness and health traits increased to $11.2 \%$. Raising the EW of Fert-I and UH-I by $50 \%$ increased the relative AMGG of fitness traits up to $19.5 \%$ and reduced the dairy traits to $68.5 \%$. The contribution of the important traits Fert-I and UH-I switched for both TMI-DHT and TMI-DHT50 from a negative direction to a positive one. All of these relations and implications on the monetary level can be seen on the natural genetic level as well. Table 5 shows the AGG for the selected traits protein yield, fertility index, and udder health index expressed in kilogram and points (Table 2: defined scale "unit"), respectively, for the different breeding strategies and TMI. The AGG for protein yield was reduced from $3.86 \mathrm{~kg}$ for TMI-R to $3.68 \mathrm{~kg}$ for TMI-DHT and to $3.25 \mathrm{~kg}$ for TMI+DHT50, assuming the CPT program. For CPT, the AGG was slightly negative for fertility index $(-0.15$ points/yr $)$ and udder health index $(-0.08$ points/yr) for TMI-R. For TMI+DHT, a slightly positive trend was observed for both traits. Using TMI+DHT50, 0.61 points in annual genetic gain can be achieved for the fertility index, and 0.50 points for the udder health index. However,

Table 4. Annual monetary genetic gain (AMGG) for the conventional progeny-testing scheme (CPT) when selected on total merit index reference (TMI-R), total merit index including direct health traits (TMI+DHT), and total merit index including direct health traits with an increased economic weight of $50 \%$ (TMI+DHT50)

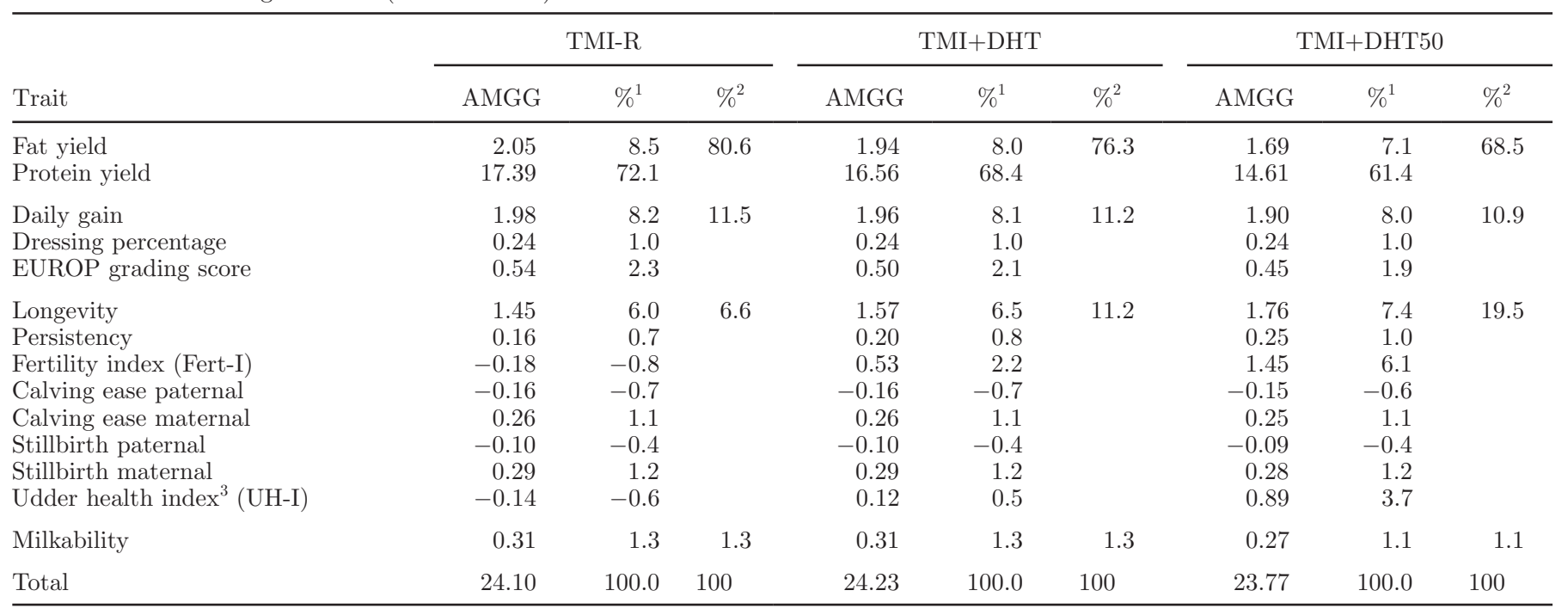

${ }^{1}$ Percentage per single trait.

${ }^{2}$ Percentage per complex (dairy, beef, fitness, and milkability).

${ }^{3} \mathrm{UH}-\mathrm{I}$ consisted of SCC only. 
Table 5. Effect on annual natural genetic gain of protein yield (Prot), fertility index (Fert-I), and udder health index (UH-I) expressed in kilograms and points, respectively, for total merit indices (TMI-R, TMI+DHT, TMI+DHT50) and breeding strategies (CPT, GS50, GS100) ${ }^{1}$

\begin{tabular}{|c|c|c|c|c|c|c|c|c|c|}
\hline \multirow[b]{2}{*}{ Strategy } & \multicolumn{3}{|c|}{ TMI-R } & \multicolumn{3}{|c|}{ TMI+DHT } & \multicolumn{3}{|c|}{ TMI+DHT50 } \\
\hline & Prot & Fert-I & UH-I & Prot & Fert-I & UH-I & Prot & Fert-I & UH-I \\
\hline $\mathrm{CPT}$ & 3.86 & -0.15 & -0.08 & 3.68 & 0.22 & 0.07 & 3.25 & 0.61 & 0.50 \\
\hline GS50 & 4.37 & -0.11 & -0.09 & 4.15 & 0.37 & 0.10 & 3.63 & 0.87 & 0.61 \\
\hline GS100 & 5.02 & -0.15 & -0.19 & 4.75 & 0.42 & 0.08 & 4.13 & 0.99 & 0.68 \\
\hline
\end{tabular}

${ }^{1} \mathrm{CPT}=$ conventional progeny-testing program; GS50 = genomic selection with $50 \%$ insemination of young bulls; GS100 = genomic selection with $100 \%$ inseminations of young bulls; TMI-R = total merit index reference (udder health index contains SCC only); TMI+DHT = total merit index with direct health traits; TMI+DHT50 = total merit index with direct health traits increased by $50 \%$ of economic weight.

the assumed situation that phenotypic information for DHT is available for all daughters of the young bulls must be noted. If this were not the case, the effect of including DHT would be lower. The results also show that the trend for udder health index is still negative if only the auxiliary trait SCC is used as an index trait (TMI-R). Generally, it should be noted that the EW for mastitis (Lind, 2007) might be underestimated because discarded milk during antibiotic treatment was not considered.

\section{Genomic Selection Strategies}

Table 6 shows the relative change in AMGG compared with the reference CPT and TMI-R without DHT. The average generation interval decreased from $5.54 \mathrm{yr}$ for CPT to $4.69 \mathrm{yr}$ for GS50 and $3.57 \mathrm{yr}$ for GS100. The number of daughters per young bull increased from 129 for CPT to 259 for GS50 and to 519 for GS100. The AMGG increased by $15 \%$ for GS50 and 30\% for GS100 compared with CPT. This superiority is less than that reported in other studies (Schaeffer, 2006; König et al., 2009; Pryce et al., 2010; Pryce and Daetwyler, 2011; Buch et al., 2012).

The similarity of selection intensities for test/young bulls in CPT, GS50, and GS100 was chosen to show the effect of using young bulls with genomic EBV only.
This study focused on the effects of different TMI and selection strategies on fitness and direct health traits only. It is expected that genomic selection, compared with CPT, would allow for a significant change in the selection intensity of young bulls, leading to higher genetic gain than the results here indicate. If the effect of different selection intensities for test/young bulls and progeny-tested bulls were modeled, the effect of genomic selection would be higher; for example, the AMGG for the former Fleckvieh breeding program (Egger-Danner et al., 2000) would be about $10 \%$ lower (€22.2/cow and year) than was achieved with the improved CPT of this study. The aspects of genotyping bull dams were also not taken into consideration. Therefore, our results cannot be used to answer the question of the full potential of genomic selection on AMGG.

Using genomic selection for TMI+DHT and TMI+DHT50 achieved almost the same progress on AMGG as did TMI-R; namely, $15 \%$ each (Table 6). Table 7 shows the relative AMMG of dairy traits and fitness and health traits for the different breeding strategies and total merit indices. For TMI-R, the relative AMMG of fitness traits increased from 6.6 to $8.9 \%$ from CPT to GS50, and from 6.6 to $8.4 \%$ from CPT to GS100, respectively. The TMI+DHT achieved $11.2 \%$ AMGG for fitness and health traits with CPT, and about $14 \%$ with genomic selection schemes (GS50 and

Table 6. Annual monetary genetic gain (\%) relative to TMI-R of CPT for total merit indices (TMI-R, TMI+DHT, TMI+DHT50) and breeding strategies (CPT, GS50, GS100) ${ }^{1}$ and corresponding generation intervals $(\mathrm{GI})$

\begin{tabular}{lcccc}
\hline & & \multicolumn{3}{c}{ Total merit index } \\
\cline { 3 - 5 } Strategy & GI $(\mathrm{yr})$ & TMI-R & TMI+DHT & TMI+DHT50 \\
\hline CPT & 5.54 & 100 & 101 & 99 \\
GS50 & 4.69 & 115 & 116 & 114 \\
GS100 & 3.57 & 130 & 132 & 129 \\
\hline
\end{tabular}

${ }^{1} \mathrm{CPT}=$ conventional progeny-testing program; GS50 = genomic selection with $50 \%$ insemination of young bulls; GS100 = genomic selection with $100 \%$ inseminations of young bulls; TMI-R $=$ total merit index reference (udder health index contains SCC only); TMI+DHT = total merit index with direct health traits; TMI+DHT50 = total merit index with direct health traits increased by $50 \%$ of economic weight. 
Table 7. Relative annual monetary genetic gain (\%) summarized for dairy traits (DT) and fitness and health traits (FIT) for total merit indices (TMI-R, TMI+DHT, TMI+DHT50) and breeding strategies (CPT, GS50, GS100) $)^{1}$

\begin{tabular}{lcccccccc}
\hline & \multicolumn{2}{c}{ TMI-R } & & \multicolumn{2}{c}{ TMI+DHT } & & \multicolumn{2}{c}{ TMI+DHT } \\
\cline { 2 - 3 } \cline { 8 - 9 } \cline { 7 - 9 } Strategy & DT & FIT & & DT & FIT & & DT & FIT \\
\hline CPT & 80.6 & 6.6 & & 76.3 & 11.2 & & 68.5 & 19.5 \\
GS50 & 79.3 & 8.9 & & 74.4 & 14.2 & & 66.2 & 22.9 \\
GS100 & 80.4 & 8.4 & & 75.1 & 14.1 & & 66.6 & 23.1 \\
\hline
\end{tabular}

${ }^{1} \mathrm{CPT}=$ conventional progeny-testing program; GS50 = genomic selection with $50 \%$ insemination of young bulls; GS100 = genomic selection with 100\% inseminations of young bulls; TMI-R = total merit index reference (udder health index contains SCC only); TMI+DHT = total merit index with direct health traits;

TMI+DHT50 = total merit index with direct health traits increased by $50 \%$ of economic weight.

GS100). For TMI+DHT50, the contribution of fitness and health traits to AMGG increased from $20 \%$ for CPT to about $23 \%$ for GS50 and GS100.

Taking into account the AGG of protein yield, an increase from 3.86 to 4.37 and $5.02 \mathrm{~kg} / \mathrm{yr}$ could be achieved for TMI-R from CPT to GS50 and GS100, respectively (Table 5). For TMI+DHT, the annual genetic genetic gain of protein yield was lower compared with that for TMI-R. For TMI+DHT50, a further reduction could be observed, whereas an annual natural genetic gain of the fertility index was clearly reinforced by GS50 and GS100 and TMI+DHT and TMI+DHT50. Although the udder health index is made more accurate by including some auxiliary traits, the same EW was used for TMI+DHT and TMI-R (Table 2). Thus, the difference between the AGG of udder health index is rather small for all breeding strategies compared with TMI-R, but the trend switches from a negative to a positive direction (Table 5). The EW of the udder health index might be undervalued, because not all relevant costs (e.g., discarded milk during antibiotic treatment) might have been considered by Lind (2007).

Otherwise, a clear positive trend for the udder health index could be achieved by using GS50 and GS100 for TMI+DHT50. This can be explained mainly by the $50 \%$ increase of the economic weight and the higher proportion of inseminations with young bulls, which resulted in reduced generation intervals and an increase in the number of daughter records per young bull.

As shown by Willam et al. (2002), a higher number of daughter records results in an increase of annual natural genetic gains for functional traits. Sorenson et al. (1999) showed that the composition of the monetary genetic gain was changed by increasing the daughter group size. In general, the shorter generation interval in GS50 and GS100 had a positive effect on fitness and health traits, and although the natural genetic gain per generation of fitness traits was lower, the natural genetic gain per year was higher due to the shorter generation interval.
If fitness traits should be considerably improved, "desired genetic gain" approaches (e.g., Yamada et al., 1975) could be considered. This raises the question of whether the possible increase in genetic gain for dairy traits should be fully exploited. A shift of the economic weight from dairy traits toward fitness and health traits could improve the latter. In Norway, the weight of clinical mastitis was increased until the desired genetic gain could be achieved, which resulted in an increase of the weight for clinical mastitis in the TMI from 3 to $21 \%$ (Heringstad, 2009; Geno, 2012). The positive effect of direct selection on health traits was emphasized by Odegård et al. (2003). König and Swalve (2006) and Heringstad et al. (2007) showed that direct selection is more effective than working with auxiliary traits.

König and Swalve (2009) were concerned about widening the gap between production and functional traits, if highly accurate genomic EBV for production traits and less accurate genomic EBV for functional traits were available. We showed that increasing the weights of low heritability functional traits in TMI could prevent this. Lillehammer et al. (2011) pointed out that genomic selection becomes more favorable for lowly heritable traits due to the increased use of information from relatives in genomic breeding values. This is made possible by marker data, providing detailed identityby-descent relationships at the DNA level. The higher amount of additional information was considered in this study by adding more daughter equivalents to the low heritability traits according to Edel et al. (2011a,b). The results showed that although there was a relative shift of AMGG toward fitness and health traits, genomic selection programs alone cannot transform a slightly negative trend into a positive one, but it can increase an existing positive trend.

Similiar results were found by Karras et al. (2011) for Brown Swiss in Germany, where a similiar total merit index is used. In that study, genomic selection decreased annual genetic gain of some fitness traits when the trend was already negative using a conven- 
tional progeny-testing program. Generally, if the natural genetic gain of traits is positive, genomic selection increases the gain.

Therefore, the composition of the traits relevant for the breeding goal needs to be considered in the TMI. The additional potential to increase the AGG for dairy traits by genomic selection offers the opportunity to balance the breeding goals and to compensate AGG for fitness and health traits. However, for an appropriate consideration of fitness and health traits in the TMI, reliable phenotypes and EW for these traits are necessary. Breeding costs based on the situation in Austria were considered in the study, but including aspects of breeding return, cost, and profit were beyond the scope of this paper.

\section{CONCLUSIONS}

Considering DHT in the TMI for Austrian Fleckvieh cattle strengthened the effect of selection for fitness and health traits and led to a slightly positive trend. An increase of the weights on fertility and udder health indices resulted in a clear positive trend for these traits. When revising breeding goals, the desired genetic gain of the different traits should be considered. The slightly negative trend for fertility index and udder health index observed when a TMI without DHT was used remained on a similar level with genomic selection. When a clear AGG was observed (e.g., for protein yield or fertility index with higher weights), genetic gain was increased by genomic selection programs. However, the genomic selection programs used in this study could not reverse a negative trend. The relative AMGG for fitness and health traits was increased by using genomic selection programs compared with the CPT program. The possible improvement of AGG for fitness and health depends highly on reliable information and appropriate EW in the TMI. Genomic selection has the potential to speed up the genetic progress, but the composition of the TMI defines the direction in which it will go.

\section{ACKNOWLEDGMENTS}

The study is part of the projects "Health monitoring system in cattle" and "Genomic evaluation for Fleckvieh." For the first project (Health monitoring system in cattle), the authors gratefully acknowledge the collaborative work of the project partners (University of Natural Resources and Life Sciences Vienna, University of Veterinary Medicine Vienna, Chamber of Veterinarians (Vienna, Austria), Chamber of Agriculture (Vienna, Austria), Animal Health Services (Bregenz, Eisenstadt, Graz, Innsbruck, Klagenfurt, Linz, Salzburg, St. Poelten, Austria), ZuchtData EDV-Dienstleistungen
GmbH (Vienna, Austria) and the Federation of Austrian Cattle Breeders with its member organisations for breeding and performance recording) to establish a health monitoring system for cattle in Austria and thank all participating farmers and veterinarians. The project was financed by the Austrian Federal Ministry of Agriculture, Forestry, Environment and Water Management (Vienna, Austria), the Austrian Federal Ministry of Health (Vienna, Austria), and the Federation of Austrian Cattle Breeders (ZAR, Vienna, Austria). For the second project (Genomic evaluation for Fleckvieh), financial support of the FFG (Austrian Research Promotion Agency, Vienna, Austria), the Federation of Austrian Fleckvieh Breeders (AGÖF, Zwettl, Austria), ZuchtData, and the cooperation for joint breeding value estimation in Germany (Bavaria, Baden-Württemberg) and Austria is gratefully acknowledged. Birgit FuerstWaltl was financially supported by the Austrian Science Fund FWF (Vienna, Austria; Elise Richter Project V43-B12).

\section{REFERENCES}

Austrian Ministry of Health. 2010. Kundmachung des TGD-Programms Gesundheitsmonitoring Rind. Accessed May 30, 2011. http://www.bmg.gv.at/cms/home/attachments/9/7/3/CH1141/ CMS1271936439807/tgdkundm74200_46-ii-b-10-10gesundheitsprogrammrindprogramm.pdf.

Buch, L. H., M. K. Sørensen, P. Berg, L. D. Pedersen, and A. C. Sørensen. 2012. Genomic selection strategies in dairy cattle: Strong positive interaction between use of genotypic information and intensive use of young bulls on genetic gain. J. Anim. Breed. Genet. 129:138-1151.

Edel, C., R. Emmerling, S. Neuner, and K.-U. Götz. 2011a. Genomische Selektion: Stand der Implementierung beim Fleckvieh. Züchtungskunde 83-4:257-265.

Edel, C., S. Schwarzenbacher, H. Hamann, S. Neuner, R. Emmerling, and K. U. Götz. 2011b. The German-Austrian genomic evaluation system for Fleckvieh (Simmental) cattle. Interbull Meeting, August, 26-28, 2011, Stavanger, Norway. Accessed Dec. 10, 2011. http://www.interbull.org/images/stories/Edel.pdf.

Egger-Danner, C., B. Fuerst-Waltl, W. Obritzhauser, C. Fuerst, H. Schwarzenbacher, B. Grassauer, M. Mayerhofer, and A. Koeck. 2012. Recording of direct health traits in Austria-Experience report with emphasis on aspects of availability for breeding purposes. J. Dairy Sci. 95:2765-2777.

Egger-Danner, C., E. Gierzinger, A. Willam, and J. Sölkner. 2000. Zuchtplanung und Optimierung der Zuchtprogramme für die Rassen Fleckvieh und Braunvieh. Forschungsbericht im Auftrag des BMLFUW, Arbeitsgemeinschaft österreichischer Fleckviehzuchtverbände; Arbeitsgemeinschaft österreichischer Braunviehzüchter. [Breeding planning and optimization of breeding programs for the Simmental and Brown breed. Research report commissioned by the BMLFUW, Association of Austrian Simmental Associations, Association of Austrian brown cattle breeders.] Austrian Federal Ministry of Agriculture, Forestry, Environment and Water Management, Vienna, Austria.

Egger-Danner, C., W. Obritzhauser, B. Fuerst-Waltl, B. Grassauer, R. Janacek, F. Schallerl, C. Litzllachner, A. Koeck, M. Mayerhofer, J. Miesenberger, G. Schoder, A. Wagner, and K. Zottl. 2010. Registration of health traits in Austria-Experience review. Page 69 in ICAR Technical Series no 14. Proc. of the 37th ICAR Biennial Session, Riga, Latvia. ICAR, Rome, Italy. 
Fuerst, C., J. Dodenhoff, C. Egger-Danner, R. Emmerling, H. Hamann, D. Krogmeier, and H. Schwarzenbacher. 2011b. Zuchtwertschätzung beim Rind-Grundlagen, Methoden und Interpretationen. Accessed Sep. 15, 2011. http://www.zar.at/download/ZWS/ZWS. pdf.

Fuerst, C., and B. Fuerst-Waltl. 2006. Züchterische Aspekte zu Kalbeverlauf, Totgeburtenrate und Nutzungsdauer in der Milchviehzucht. Züchtungskunde 78:365-383.

Fuerst, C., and B. Fuerst-Waltl. 2011. Zusammenhänge zwischen Eutergesundheit, Exterieur und Co. Seminar des genetischen Ausschusses der ZAR, Salzburg, März 2011. Accessed Aug. 15, 2011. http://www.zar.at/article/articleview/44278/1/306.

Fuerst, C., A. Koeck, C. Egger-Danner, and B. Fuerst-Waltl. 2010. Phenotypic and genetic relationships between clinical mastitis and udder conformation traits in Austrian Fleckvieh cattle. Proc. 9th World Congr. Genet. Appl. Livest. Prod., Leipzig, Germany. Gesellschaft für Tierzuchtwissenschaften e.V, Gießen, Germany

Fuerst, C., A. Koeck, C. Egger-Danner, and B. Fuerst-Waltl. 2011a. Routine genetic evaluation for direct health traits in Austria and Germany. Interbull Meeting, Stavanger, Norway. Accessed Jan. 5, 2012. http://www.interbull.org/images/stories/Fuerst.pdf.

Fuerst-Waltl, B., B. Baumung, C. Fuerst, A. Köck, W. Obritzhauser, H. Schwarzenbacher, J. Sölkner, A. Willam, P. Winter, and C. Egger-Danner. 2010. Gesundheitsmonitoring Rind: Entwicklung einer Zuchtwertschätzung für Gesundheitsmerkmale. Abschlussbericht zum Forschungsprojekt 100250 BMLFUW-LE.1.3.2/0043II/1/2007. Accessed Sep. 15, 2011. http://www.dafne.at/dafne_ plus_homepage/index.php?section $=$ dafneplus\&content $=$ result\&\& come_from $=$ homepage\&project_id $=2704$.

Geno. 2012. Total Merit Index-Norwegian Red. Accesssed Mar. 10, 2012. http://www.genoglobal.no/no/Home/Norwegian-Red-Characteristics/Total-merit-index.

Hansen Axelsson, H., K. Johansson, S. Eriksson, K.-J. Petersson, L. Rydhmer, and J. Philipsson. 2011. Selection of bull dams for production and functional traits in an open nucleus herd. J. Dairy Sci. 94:2592-2600.

Heringstad, B. 2009. Use of health data for dairy cows - Experiences from Norway. Meeting in Freistadt, Austria, December 1, 2009. Accessed Nov. 10, 2011. http://cgi.zar.at/download/Newsletter/ Bjorg.pdf.

Heringstad, B., G. Klemetsdal, and J. Ruane. 2001. Responses to selection against clinical mastitis in the Norwegian cattle population. Acta Agric. Scand. A Anim. Sci. 51:155-160.

Heringstad, B., G. Klemetsdal, and T. Steine. 2003. Selection response for clinical mastitis and protein yield in two Norwegian dairy cattle selection experiments. J. Dairy Sci. 86:2990-2999.

Heringstad, B., G. Klemetsdal, and T. Steine. 2007. Selection responses for disease resistance in two selection experiments with Norwegian red cows. J. Dairy Sci. 90:2419-2426.

Karras, K., P. Herold, H. Hamann, A. Weidele, and A. Valle Zarate. 2011. Genomische Selektion beim Braunvieh: Auswirkungen auf Zuchtfortschritt und Züchterungsgewinn. Züchtungskunde 83:333-349.

Koeck, A., C. Egger-Danner, C. Fuerst, W. Obritzhauser, and B. Fuerst-Waltl. 2010a. Genetic analysis of reproductive disorders and their relationship to fertility and milk yield in Austrian Fleckvieh dual purpose cows. J. Dairy Sci. 93:2185-2194.

Koeck, A., B. Heringstad, C. Egger-Danner, C. Fuerst, P. Winter, and B. Fuerst-Waltl. 2010b. Genetic analysis of clinical mastitis and somatic cell count traits in Austrian Fleckvieh cows. J. Dairy Sci. 93:5987-5995.

König, S., and H. Swalve. 2009. Application of selection index calculations to determine selection strategies in genomic breeding programs. J. Dairy Sci. 92:5292-5303.

König, S., and H. H. Swalve. 2006. Modellkalkulationen zu züchterischen Möglichkeiten auf Klauengesundheit beim Milchrind. Züchtungskunde 78:345-356.

Lassen, J., M. K. Sorensen, P. Madsen, and V. Ducrocq. 2007. A stochastic simulation study on validation of an approximate mul- titrait model using preadjusted data for prediction of breeding values. J. Dairy Sci. 90:3002-3011.

Lillehammer, M., T. H. E. Meuwissen, and A. K. Sonesson. 2011. A comparision of dairy cattle breeding designs that use genomic selection. J. Dairy Sci. 94:493-500.

Lind, B. 2007. Ableitung der Wirtschaftlichkeitskoeffizienten und optimalen Indexgewichte des Gesamtzuchtwertes für die deutschen Milch- und Zweinutzungsrassen unter Berücksichtigung aktueller und erwarteter zukünftiger Rahmenbedingungen. PhD Diss. Georg-August-Universität, Göttingen, Germany.

Miesenberger, J. 1997. Zuchtzieldefinition und Indexselektion für die österreichische Rinderzucht. PhD Diss. Univ. für Bodenkultur Wien, Austria.

Neuner, S., and K.-U. Götz. 2011. Auswirkung der genomischen Selektion auf den Zuchtfortschritt in funktionalen Merkmalen. Züchtungskunde 83:350-360.

Odegård, J., G. Klemetsdal, and B. Heringstad. 2003. Genetic improvement of mastitis resistance: Validation of somatic cell score and clinical mastitis as selection criteria. J. Dairy Sci. 86:41294136.

Oltenacu, P. A., and B. Algers. 2005. Selection for Increased Production and the Welfare of Dairy Cows: Are new Breeding Goals Needed? Ambio Vol. 34, No. 4-5, June 2005. Royal Swedish Academy of Sciences, Stockholm.

Phillipsson, J., and B. Lindhe. 2003. Experiences of including reproduction and health traits in Scandinavian dairy cattle breeding programmes. Livest. Prod. Sci. 83:99-112.

Pryce, J. E., and H. D. Daetwyler. 2011. Designing dairy cattle breeding schemes under genomic selection: A review of international research. Anim. Prod. Sci. 52:107-114. http://dx.doi.org/10.1071/ AN11098.

Pryce, J. E., M. E. Goddard, H. W. Raadsma, and B. J. Hayes. 2010. Deterministic models of breeding scheme designs that incorporate genomic selection. J. Dairy Sci. 93:5455-5466.

Schaeffer, L. R. 2006. Strategy for applying genome-wide selection in dairy cattle. J. Anim. Breed. Genet. 123:218-223.

Sorenson, M. K., P. Berg, J. Jensen, and L. G. Christensen. 1999. Stochastic simulation of breeding schemes for dairy cattle. Page 33 in Book of Abstracts of the 50th Ann. Meeting of the EAAP, Zurich, Switzerland. Wageningen Academic Publishers, Wageningen, the Netherlands. Acccessed Dec. 15, 2011. http://agtr.ilri.cgiar. org/agtrweb/documents/Library/docs/Interbull/bulletin23_files/ Docs/sorensen.pdf.

Svendsen, M., and I. M. A.-Ranberg. 2000. Genetic evaluation for functional traits in Norway. Interbull Bulletin 25:135-138. Accessed Jan. 5, 2012. http://www-interbull.slu.se/bulletins/bulletin25/svendsen.pdf.

Veerkamp, R. F., B. Beerda, and T. von der Lende. 2003. Effects of genetic selection for milk yield on energy balance, levels of hormones and metabolites in lactating cattle, and possible links to reduced fertility. Livest. Prod. Sci. 83:257-265.

Willam, A., C. Egger-Danner, J. Sölkner, and E. Gierzinger. 2002. Optimization of progeny testing schemes when functional traits play an important role in the total merit index. Livest. Prod. Sci. $77: 217-225$.

Willam, A., G. Nitter, H. Bartenschlager, K. Karras, E. Niebel, H.U. Graser. 2008. ZPLAN-Manual for a PC-Program to Optimize Livestock Selection Schemes. Manual Version 2008 for Source Code "z10.for". University of Natural Resources and Applied Life Sciences, Department of Sustainable Agricultural Systems, Division Livestock Sciences, Vienna, Austria.

Willam, A., and H. Simianer. 2011. Tierzucht. Grundwissen Bachelor. Verlag Eugen Ulmer KG, Stuttgart, Germany.

Yamada, Y., K. Yolouchi, and A. Nishida. 1975. Selection index when genetic gains of individual traits are of primary concern. Jpn. J. Genet. 50:33-41.

ZuchtData. 2010. ZuchtData Jahresbericht, 2010. ZuchtData EDVDienstleistungen GmbH, Vienna. Accessed Jul. 30, 2011. http:// www.zuchtdata.at/article/archive/25. 